\title{
The HR2 polymorphism N140I in the HIV-1 gp41 combined with the HR1 V38A mutation is associated with a less cytopathic phenotype
}

\author{
Francesc Cunyat', Silvia Marfil', Elisabet García', Valentina Svicher², Nuria Pérez-Alvárez ${ }^{3,4}$, Marta Curriu',
} Carlo Federico Perno ${ }^{2}$, Bonaventura Clotet ${ }^{1,3}$, Julià Blanco ${ }^{1}$ and Cecilia Cabrera ${ }^{1 *}$

\begin{abstract}
Background: Resistance to the fusion inhibitor enfuvirtide (ENF) is achieved by changes in the gp41 subunit of the HIV envelope glycoprotein (Env). Specific ENF-associated mutational pathways correlate with immunological recovery, even after virological failure, suggesting that the acquisition of ENF resistance alters gp41 pathogenicity. To test this hypothesis, we have characterized the expression, fusion capability, induction of $\mathrm{CD}^{+} \mathrm{T}$ cell loss and single $C D 4^{+} T$ cell death of 48 gp41 proteins derived from three patients displaying different amino acids ( $N$, $T$ or I) at position 140 that developed a V38A mutation after ENF-based treatment.
\end{abstract}

Results: In all cases, intra-patient comparison of Env isolated pre- or post-treatment showed comparable values of expression and fusogenic capacity. Furthermore, Env with either $\mathrm{N}$ or $\mathrm{T}$ at position 140 induced comparable losses of $\mathrm{CD}^{+} \mathrm{T}$-cells, irrespective of the residue present at position 38. Conversely, Env acquiring the V38A mutation in a 140 l background induced a significantly reduced loss of $\mathrm{CD}^{+} \mathrm{T}$ cells and lower single-cell death than did their baseline controls. No altered ability to induce single-cell death was observed in the other clones.

Conclusions: Overall, primary gp41 proteins with both V38A and N140I changes showed a reduced ability to induce single cell death and deplete $\mathrm{CD}^{+} \mathrm{T}$ cells, despite maintaining fusion activity. The specificity of this phenotype highlights the relevance of the genetic context to the cytopathic capacity of Env and the role of ENFresistance mutations in modulating viral pathogenicity in vivo, further supporting the hypothesis that gp41 is a critical mediator of HIV pathogenesis.

Keywords: HIV, gp41, enfuvirtide, single cell death, fusogenicity

\section{Background}

HIV infection causes a progressive depletion of $\mathrm{CD}^{+} \mathrm{T}$ cells, which leads to the development of AIDS [1,2]. Although $\mathrm{CD}^{+} \mathrm{T}$ cell loss in HIV infection is a multifaceted process [3-5], the death of bystander $\mathrm{CD} 4^{+} \mathrm{T}$ cells seems to be one of the main contributors to HIVinduced pathogenesis [6-8]. Various mechanisms have been proposed to explain the destruction of bystander $\mathrm{CD}^{+}{ }^{+} \mathrm{T}$ cells, including apoptosis, autophagy or abortive infection [6,8-11]. The HIV envelope (Env) glycoprotein, which mediates viral entry into the host cell by fusion of

\footnotetext{
* Correspondence: ccabrera@irsicaixa.es

'IrsiCaixa-HIVACAT, Institut de Recerca en Ciències de la Salut Germans Trias i Pujol (IGTP), Hospital Germans Trias, Universitat Autònoma de Barcelona, Badalona 08916 Barcelona, Catalonia, Spain

Full list of author information is available at the end of the article
}

the viral and host cell membranes (reviewed in [12-14]), is one of the viral factors involved in the death of both infected $[15]$ and bystander cells $[7,8,16]$. The Env complex is composed of two non-covalently linked subunits, namely, the surface glycoprotein (gp120) and the transmembrane glycoprotein (gp41), and is displayed as heterotrimers on the surface of virions and infected cells [14,17-20]. Viral entry is a multistep phenomenon: the interaction of gp120 with the host cell surface CD4receptor, and either CCR5 or CXCR4 coreceptor enables gp41 subunits to trigger hemifusion events, thereby leading to fusion. The HIV gp41 is a classic type 1 fusion protein that contains three domains: an ectodomain, a membrane-spanning domain, and a long intracytoplasmic segment. The ectodomain of gp41 consists 
of an N-terminal fusion peptide followed by two conserved coiled-coil domains that are referred to as $\mathrm{C}$ - and $\mathrm{N}$-terminal heptad repeats (HR1 and HR2), which are connected by a non-helical loop region. These HR interact with each other in a leucine zipper-like fashion to mediate membrane fusion [21]. Synthetic peptides that bind to one of the HR motifs interfere with their interaction and thus inhibit viral entry [22,23].

Enfuvirtide (ENF, T-20) is the first peptide approved for clinical use in HIV salvage therapy. This drug is a 36-amino acid peptide that was designed based on the amino-acid sequence of the HR2 domain of the gp41 subunit. This peptide prevents the HR1-HR2 interaction by binding to the HR1 domain $[22,24,25]$. The therapeutic benefits of ENF therapy have been demonstrated by increases in $\mathrm{CD}^{+} \mathrm{T}$ cell counts and a significant reduction in HIV RNA levels [26-28]. Nevertheless, ENFresistant $\mathrm{HIV}-1$ variants rapidly emerge under drug pressure when virus replication is not completely suppressed [29-31]. Sequence analysis of ENF-resistant viral populations revealed the acquisition of mutations within the HR1 domain at positions 36-38 (GIV) [29,30], which were associated with a reduction in viral infectivity, probably as a consequence of impaired interaction between HR1 and HR2 [32,33]. However, certain compensatory mutations within HR2 may arise and restore viral infectivity [29,32,34-37]. Despite virological failure, specific mutations (the cluster V38A+N140I) have been associated with an increase in $\mathrm{CD} 4^{+} \mathrm{T}$ cell counts [38-40].

The Env glycoprotein plays a crucial role in the depletion of $\mathrm{CD}^{+} \mathrm{T}$ cells by inducing the death of single bystander cells, which is mediated by gp41 [41,42]. Therefore, changes in gp41 that emerge under ENF pressure could induce a change in the viral pathogenicity. Although site-directed point mutations at position 38 in gp41 have been shown to exhibit deficiency in cell-to-cell fusion activity and apoptosis induction in vitro and in a humanized mouse model $[43,44]$, it is important to note that the genetic background has been proven relevant for functional evaluation of the ENFresistant Envs because there may be compensatory changes that restore the infectivity of the virus $[32,34,36,37,45,46]$.

The objective of the current study was to evaluate the pathogenicity of several patient-derived gp41 proteins isolated from highly experienced patients receiving an ENF-containing salvage therapy and whether changes at position 38 and 140 in gp41 have an impact in the biological properties of patient-isolated Envs. Our results indicate that the primary gp41 Env proteins, with both V38A and N140I changes, induced lower levels of single-cell death and depletion of $\mathrm{CD}^{+}{ }^{+} \mathrm{T}$ cells, although they retained cell-to-cell fusion activity. However, the mutation V38A in the context of a $140 \mathrm{~N}$ or $140 \mathrm{~T}$ change did not alter Env functions, underscoring the importance of the Env genetic background in the modulation of the cytopathic effects of the HIV-1 Env glycoproteins.

\section{Results and discussion}

\section{Patients and envelope constructions}

In a previous report, we characterized gp 41 proteins derived from 13 heavily pre-treated HIV-1-infected patients receiving an ENF-containing salvage therapy [29]. Several drug resistance-associated mutations were detected along the entire gp41 ectodomain, mainly mapping in the HR1 domain at positions 36, 38 and 43. Clinical findings have suggested that certain ENF-resistant mutants arising during salvage therapy, specifically, the cluster V38A+N140I, are associated with an increase in $\mathrm{CD}^{+}$cell counts, even after virological failure $[38-40,43,44]$. We therefore reasoned that gp41 proteins derived from patients with different combinations of amino acids at positions 38 and 140 could have different pathogenic effects. We chose to study the gp41 proteins derived from three patients: patients 1, 9 and 10, who had mutations associated with ENF resistance at position 38 in the gp41 viral protein but differed in the amino acid found at position 140 [29]. Two plasma samples from each patient, which were collected at baseline and during treatment, were used to construct gp160 hybrid proteins (all bearing the gp120 from an NL4-3 virus and the gp41 derived from the patients). Table 1 summarizes the characteristics of the patients at the time points of viral RNA isolation. At least 15 recombinant expression plasmids were constructed from each sample, and all recombinant plasmids were fully sequenced to verify that the gp120 sequence present was conserved among the clones and that the NL4-3 wt sequence remained unchanged (data not shown). The amino acids at positions 38 and 140 of gp41 were subsequently determined, and 48 recombinant plasmids were finally selected (Figure 1). Among these plasmids, 13 clones were derived from patient 9, containing an asparagine at position $140(140 \mathrm{~N})$ and the wild-type (wt) amino acid at position $38(38 \mathrm{~V})$ or an alanine at position 38 (38A) ( $\mathrm{n}=5$ and $\mathrm{n}=8$, respectively); 19 clones were derived from patient 10 , who contained the substitution N140T and the wt $38 \mathrm{~V}(\mathrm{n}=10)$ or the V38A mutation $(\mathrm{n}=9)$; and finally, 16 clones were derived from patient 1, who had the polymorphism N140I and the wt amino acid at position $38(\mathrm{n}=10)$ or the V38A mutation ( $n=6$, Figure 1$)$. Since we cloned the full gp41 protein present in vivo, we were able to identify other changes throughout the gp41 protein in addition to the changes at positions 38 and 140. Changes were found primarily in the HR2 domain, but also upstream 
Table 1 Characteristics of the three patients receiving an enfuvirtide-containing salvage therapy when samples were collected

\begin{tabular}{|c|c|c|c|c|c|}
\hline Patient $^{a}$ & Sample & $\begin{array}{c}\text { Weeks on } \\
\text { ENF treatment }\end{array}$ & $\begin{array}{c}\text { Plasma viral } \\
\text { load (copies/mL) }\end{array}$ & $\begin{array}{c}\mathrm{CD4}^{+} \text {cell } \\
\text { count }(\text { cells/ } / \mu \mathrm{l})\end{array}$ & $\begin{array}{l}\text { No. of expression } \\
\text { plasmids constructed }\end{array}$ \\
\hline \multirow[t]{2}{*}{$140 \mathrm{~N}(9)$} & $140 \mathrm{~N}$ & 0 & 366357 & 491 & 5 \\
\hline & V $38 \mathrm{~A} 140 \mathrm{~N}$ & 24 & 8536 & 700 & 8 \\
\hline \multirow[t]{2}{*}{ N140T (10) } & N140T & 0 & 141497 & 13 & 10 \\
\hline & V38A N140T & 4 & 332794 & 13 & 9 \\
\hline \multirow[t]{2}{*}{ N140I (1) } & $\mathrm{N} 140 \mathrm{l}$ & 0 & 33470 & 145 & 10 \\
\hline & V38A N140I & 12 & 10806 & 150 & 6 \\
\hline
\end{tabular}

${ }^{\mathrm{a}}$ The patient IDs from a previous work [29] are indicated in parentheses.

of the HR1 domain, in the HR1 domain and in the loop section. Most of the recombinant plasmids constructed from sequences obtained during ENF treatment carried the V38A mutation as the only change associated with ENF resistance, although four clones derived from the $140 \mathrm{~N}$ patient carried the $\mathrm{N} 42 \mathrm{~T}$ mutation, and three others showed the N126K mutation. The analysis of a caveolin-1 binding motif in the gp41 protein, which has been recently reported to affect HIV-1 pathogenesis
[47], showed that only one plasmid from the patient harboring the $140 \mathrm{~N}$ background carried an $\mathrm{M}$ to V substitution at position 115 . The remaining plasmids constructed with sequences from this patient and all of the recombinant constructs from the other two patients showed no changes in this region before or after treatment (Figure 1). Our cloning approach, using only the gp41 of the patient instead of the entire Env (gp41 + gp120), allows us to specifically assess the effect of

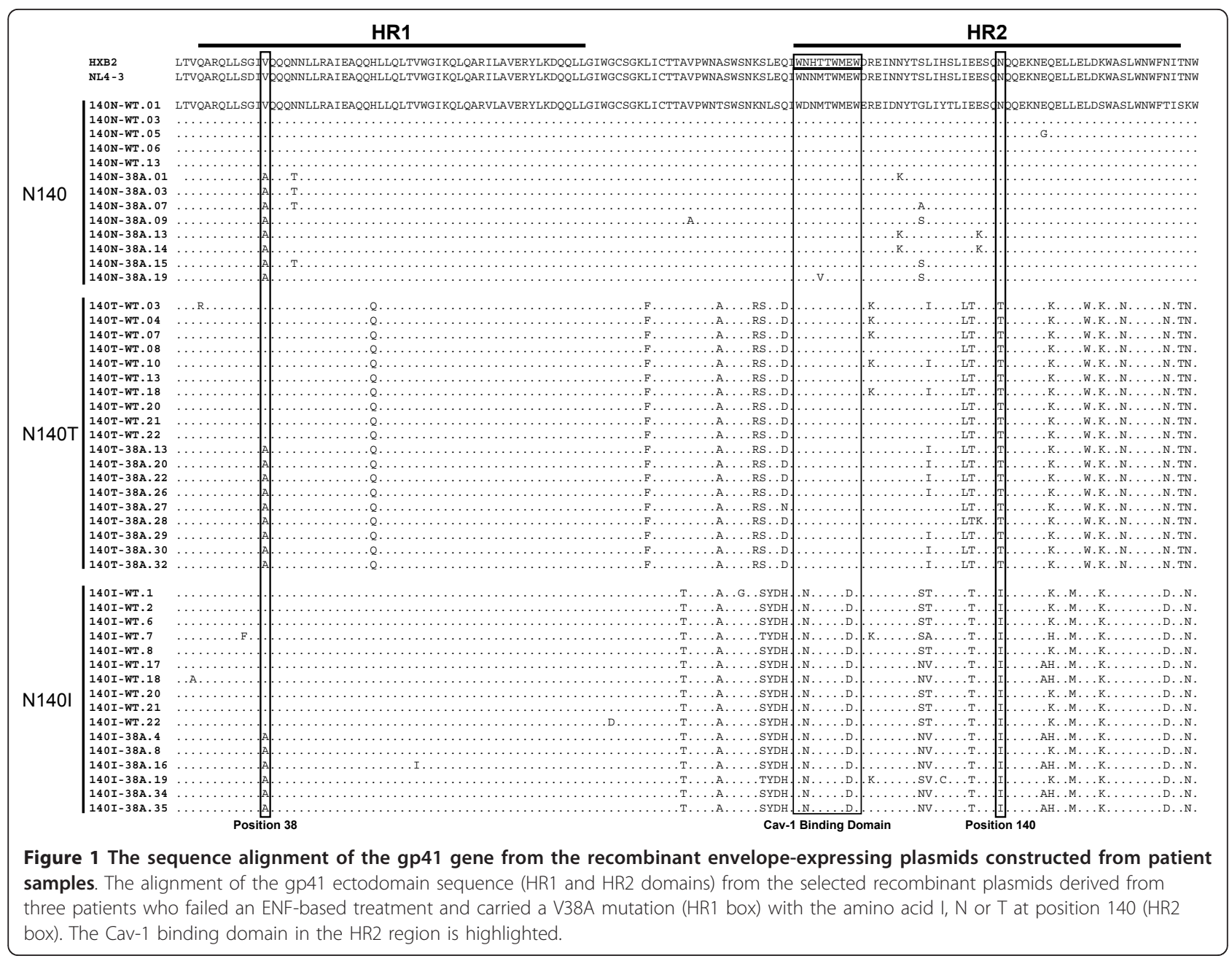


certain ENF resistance mutations on gp41 pathogenesis, avoiding additional effects of changes in gp120 protein itself and importantly avoiding any interference of the CXCR4 or the CCR5 coreceptor use, which is a major determinant of Env pathogenicity both in vivo and in vitro $[48,49]$. If viruses with different coreceptor usage had been compared, we would not have been able to discern the Env subunit responsible for the observed differences.

\section{Cell surface expression of HIV-1 recombinant envelope glycoproteins}

After the optimization of the transfection and the cell surface staining procedures (Cunyat F, Curriu M et al., J Biomolecular Screening, in press), HeLa cells were transiently transfected with the 48 recombinant Env-expressing plasmids, and 24 hours post-transfection, the cell surface expression of Env was analyzed using a primary antibody against the gp120 subunit (2G12). An antigp120 antibody was used, instead of an anti-gp41 antibody, to avoid artifacts due to changes in the gp 41 protein that could affect the binding of the antibody. All tested Envs were expressed on the cell surface with expression levels ranging from $2.7 \%$ to $29.9 \%$ of positive cells (Figure 2A). When an inter-patient comparison was performed by grouping all of the Envs obtained from each patient irrespective of the time point, a significantly different percentage of Env-expressing cells was observed between plasmids constructed from the $140 \mathrm{~N}$ and N140T-carrying patients. The lowest percentage of Env-positive cells was observed for the $140 \mathrm{~N}$ constructs $($ mean $=11.40+/-3.9)$, whereas the highest percentage of Env-expressing cells was observed for the N140T clones $($ mean $=15.91+/-4.4)$ (Figure $2 \mathrm{~A})$. However, when we analyzed the percentage of cells expressing the Env constructs obtained from the same patient by comparing clones displaying or not the V38A mutation (an intra-patient comparison after and before treatment, respectively), the Env expression was similar in all cases (Figure 2A). In addition to determining the percentage of positive cells, the Env expression levels, which could play an important role in Env pathogenesis, were evaluated. There were no differences in the Env expression levels between constructs containing wt gp41 and those containing the $38 \mathrm{~A}$ mutation from the same patient, as determined by the geometric mean fluorescence intensity (data not shown), or the relative fluorescence intensity [50], which is a measure of the total Env expression (Figure 2B). Thus, the intra-patient comparisons suggest that the expression of Env does not change upon acquisition of the 38A mutation, and the level of Env expression is an intrinsic characteristic of the particular Env carried by each infected patient. These results allowed us to analyze the cytopathic effects of Env without correcting for cell surface expression of Env.

\section{Analysis of the Env protein fusogenicity}

The function of the HIV Env glycoprotein is to facilitate the entry of the viral nucleocapsid into the target cell. This process has an important role in HIV pathogenesis, and the fusogenic activity of HIV Env has long been associated with cytopathic effects [50,51] both in vitro and in vivo [52-54]. In agreement with this property, it has been described that single-amino-acid mutations in the ectodomain (V38A/E) or transmembrane regions of gp41 reduce cell-to-cell fusion activity of the virus $[43,55]$. A number of different assay systems have been reported to measure the HIV envelope activity. However, we have described the importance of selecting an appropriate cell line to express Env when the cytopathic properties of clinically derived gp41 glycoproteins in vitro are evaluated (Cunyat F, Curriu M et al., J Biomolecular Screening, in press). In this study, two envelopeexpressing effector cell lines (293T and HeLa cells) were compared to evaluate the activity of patient-derived Envs: fusion, absolute cell loss and single cell death. The results showed a differential behaviour between both cell lines. 293T effector cells seem to have a rapid formation of the fusion pore, generating high levels of fusion and lower levels of single cell death. In contrast, HeLa cells would fuse slowly, inducing greater extents of single cell death. Thus, HeLa cells should be preferentially used for the evaluation of cell death parameters, and the 293T cell line should be used when envelopes with low fusogenic capacity are evaluated. Based on this recommendation, all of our recombinant Envs were first expressed in 293T cells, and assayed for fusion activity. Detectable fusion was observed for all Env, showing fusion levels over the 50\% when compared with an NL4-3 wt Env (data not shown). Since all our Env were fusogenic, we used HeLa cell as the effector cell line in our assays. These cells were transiently co-transfected with the Env- and pcTat-expressing plasmids and cocultured with the reporter TZM-bl cells. After six hours of coculture, the luminescence in the sample was measured, and the relative fusion capacity of each recombinant Env was calculated in comparison to the fusion values obtained using the NL4-3 wt Env, which was used as a control (100\%). The level of fusion of the Envs obtained from different patients (inter-patient analysis) showed significant differences, underscoring that the virus each patient carries may have an Env with a distinct fusogenic capacity which, in this case, is determined by gp41. Differences in fusion were not correlated with the expression level of Env on the cell surface because a higher expression level did not result 


\section{A}
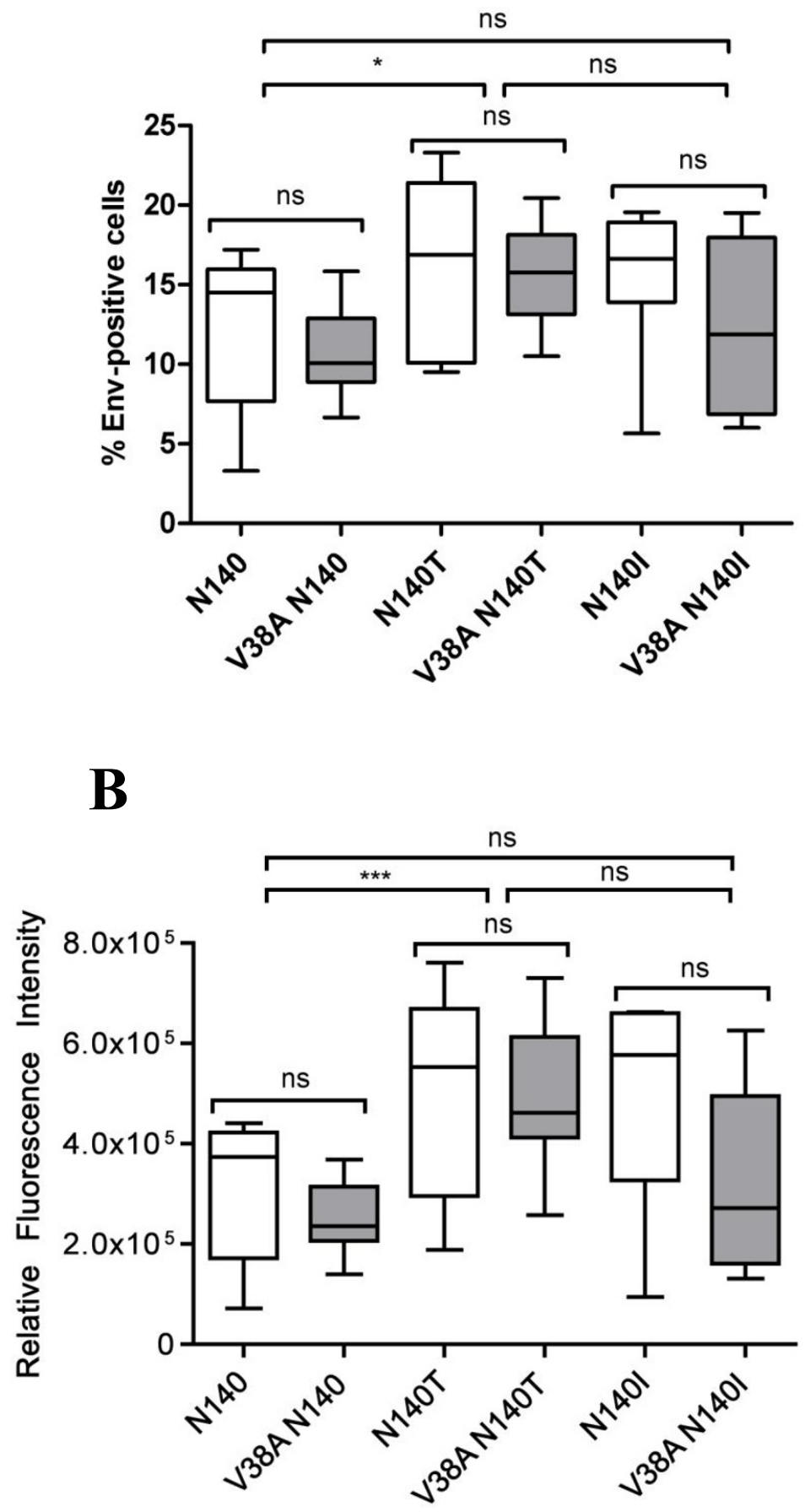

Figure 2 The expression of functional recombinant envelopes on transfected HeLa cells. Env-expressing plasmids constructed from three patients carrying an amino acid N, T or I at position 140 with (V38A) without substitutions at position 38 of gp41 were transfected into HeLa cells. The surface expression of Env was analyzed 24 hours post-transfection by staining the cells with the 2 G12 antibody. Env expression was determined by the percentage of Env-positive cells in an inter-patient analysis using the clones constructed from each patient or in an intrapatient analysis using clones constructed from baseline and after treatment (V38A) samples (A). The total level of Env expression was determined by calculating the relative fluorescence intensity (RFI $=\%$ of Env-positive cells $\times$ geometric mean fluorescence of Env-positive cells) in an intrapatient analysis (B). Baseline samples (white boxes) and V38A samples (gray boxes). The boxes represent the median and interquartile range of the values. The median values were compared using a nonparametric Mann Whitney test. ${ }^{*} p<0.05,{ }^{* * *} p=0.0006$, and ns denotes nonsignificant differences. 
in more fusion (Figures 2 and 3). However, in contrast to previously published data $[43,44]$, when intra-patient analyses were performed, the fusogenic activities of all recombinant Envs obtained from each patient were similar, indicating that in a full-length gp41 background, the V38A mutation did not impair the cell-to-cell fusion activity of Env in the presence of the amino acids $\mathrm{N}, \mathrm{T}$ or I at position 140 (Figure 3). Site-directed point mutations at position 38 in gp41 resulted in reduced cell-tocell fusion and apoptosis induction, although viral replication in vitro and in humanized mice was not affected $[43,44]$. The differences between our data and those obtained using site-directed mutants could be explained by the fact that genetic context is extremely important in the characterization of the biological properties of Env. In the case of ENF resistance, previous studies have shown that the Env genetic background contributes to both the ENF resistance and Env function. The selection of resistance is a coevolutionary process in which HR1 mutations are selected in combination with Env variants that permit optimal phenotypic expression of HR1 mutations [45]. It is well-established that HR1 mutations introduced out of context (i.e., in a gp 41

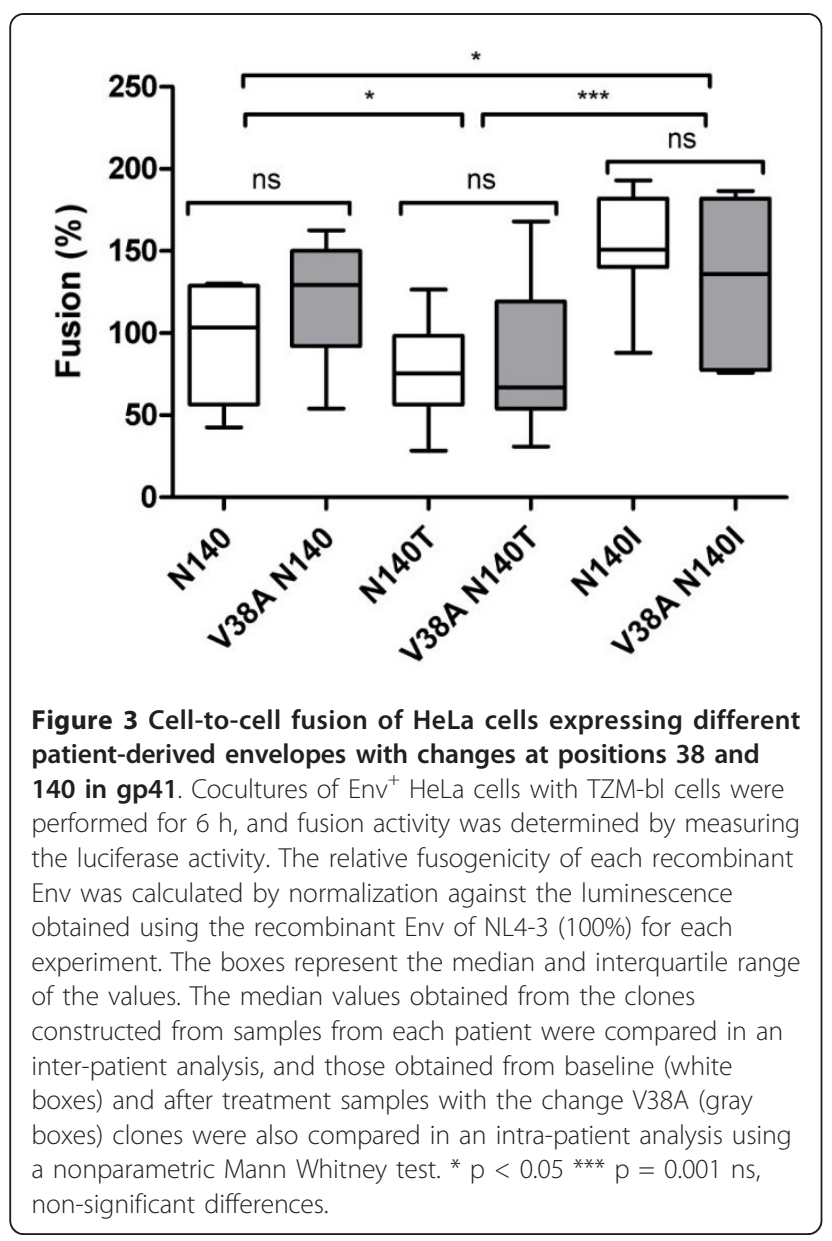

where they were not originally found) negatively impact the rate of membrane fusion; while the introduction of changes in HR2, or even in gp120, can compensate for this functional defect [29,32,34-37]. Indeed, point mutations introduced into gp41 may perturb the folding of the protein into a six-helix bundle along the HR1 and HR2 coiled-coil domains. In contrast, a native gp41 background may stabilize the fusogenic six-helix bundle with compensatory changes in the HR1 mutants, thereby minimizing the effect of the original mutation.

\section{Quantification of envelope-induced absolute loss of CD4 ${ }^{+}$ T cells}

In addition to fusion activity, HIV Env-mediated cytopathic effects were evaluated by quantifying the absolute loss of purified primary $\mathrm{CD} 4^{+} \mathrm{T}$ cells cocultured with HeLa cells that expressed the recombinant Envs. Despite a similar fusogenic capacity of the wt recombinant Envs and those bearing mutations at position 38, the absolute loss of $\mathrm{CD}^{+} \mathrm{T}$ cells was significantly lower after exposure to Envs containing the V38A mutation in a N140I background than after exposure to wt Env (18.1\% and $31.3 \%$, respectively. $\mathrm{P}=0.022$ ) (Figure $4 \mathrm{~A}$ ). In contrast, Env proteins containing either an $\mathrm{N}$ or a $\mathrm{T}$ at position 140 induced comparable levels of absolute $\mathrm{CD} 4^{+} \mathrm{T}$ cell loss, irrespective of the amino acid present at position 38 (33.4\% 38V and $25.6 \% 38 \mathrm{~A}$ in an $140 \mathrm{~N}$ background and $15.8 \%$ and $17.0 \%$, respectively, with a $140 \mathrm{~T}$ change, Figure 4A).

\section{Analysis of envelope-induced bystander apoptosis}

The Env-mediated depletion of the $\mathrm{CD} 4^{+} \mathrm{T}$ cells may result from syncytium formation (directly related to fusogenicity values) or from gp41-mediated bystander apoptosis of single $\mathrm{CD} 4^{+} \mathrm{T}$ cells. Apoptosis is a crucial factor contributing to the loss of $\mathrm{CD}_{4}^{+} \mathrm{T}$ cells, and the extent of immune-cell apoptosis is correlated with AIDS progression [56]. Importantly, apoptosis of bystander, uninfected cells is one of the major processes involved in the destruction of immune cells during HIV infection [8] because the majority of apoptotic $\mathrm{CD} 4^{+} \mathrm{T}$ cells in the peripheral blood and lymph nodes are uninfected in patients infected with HIV $[57,58]$. The Env-induced death of single bystander cells is related to gp41mediated membrane hemifusion processes between Envexpressing cells and target cells [41,42]. This gp41 dependence suggests that drugs targeting gp41 function may alter HIV pathogenesis by inducing changes in the gp41 sequence. Consistent with this, certain ENF-resistant mutations arising during salvage therapy, specifically changes at position 38 in gp41, were associated with an immunological benefit, even after virological failure $[39,40]$. Additionally, the increase in $\mathrm{CD}^{+} \mathrm{T}$ cells was enhanced by the concomitant polymorphism 


\section{A}

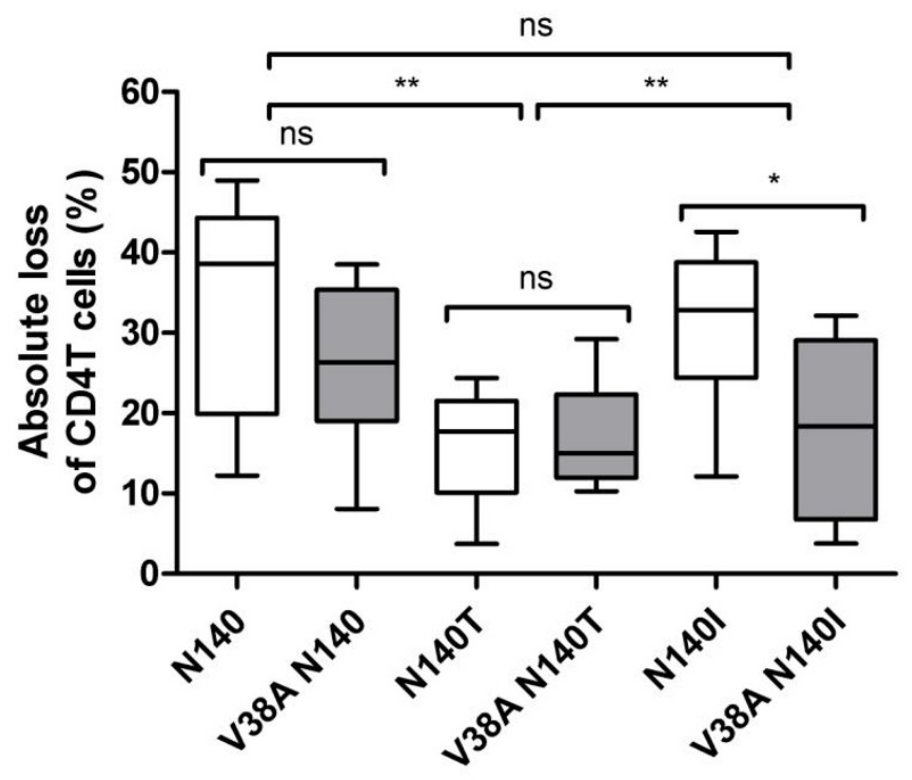

B

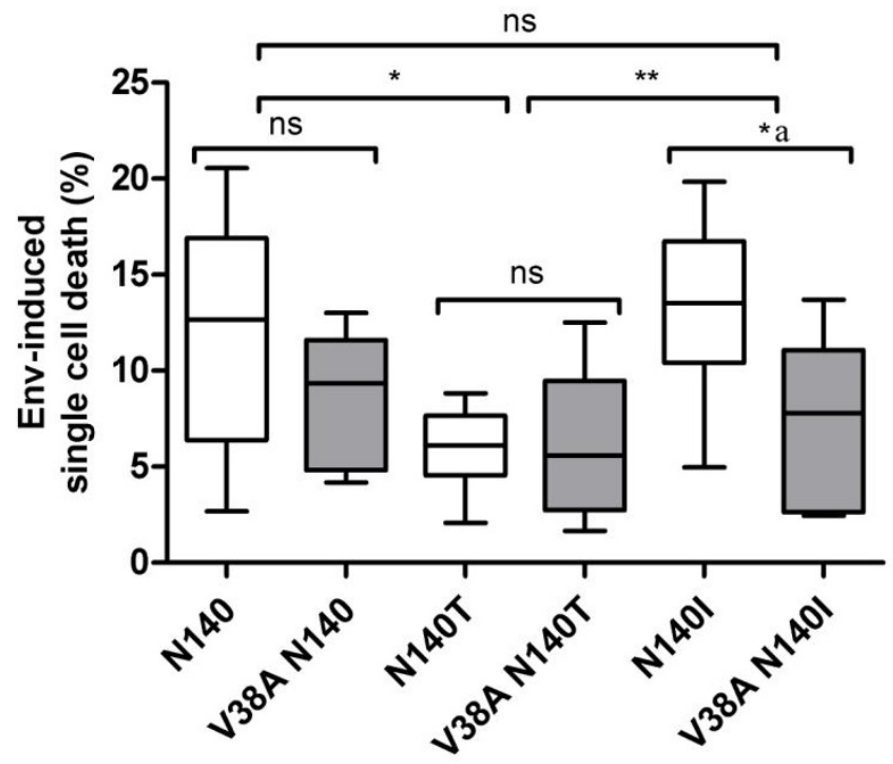

Figure 4 Envelope-induced cytopathicity in $\mathrm{CD}^{+} \mathbf{T}$ cells. Envelope-mediated absolute $\mathrm{CD}^{+} \mathrm{T}$ cell depletion. Absolute loss of $\mathrm{CD} 4^{+} \mathrm{T}$ cells in cocultures of Env-expressing HeLa cells and purified CD4 ${ }^{+} \mathrm{T}$ cells was determined. Single living $\mathrm{CD} 4^{+} \mathrm{T}$ cells were morphologically gated, and the absolute loss of $\mathrm{CD}^{+} \mathrm{T}$ cells in the coculture was quantified by the addition of PE-labeled microbeads. ${ }^{*} p=0.022,{ }^{* *} p<0.007$ (A). Bystander apoptosis induced by envelopes harbouring changes at position 38 and 140 in gp41. Cocultures of primary CD4 ${ }^{+}$T cells, previously stained with the DDAO cell tracker, and HeLa Env ${ }^{+}$cells were performed and analyzed after 24 hours by flow cytometry. Single, nonfused CD4 ${ }^{+} \mathrm{T}$ cells were gated by the forward- vs. side-scatter characteristics and by being positives for the cell tracker. Detection of early (PI'DIOC) and late apoptotic (PI $\left.{ }^{+} \mathrm{DIOC}\right)$ populations were determined in this gated population for each recombinant Env in the presence or absence of the coreceptor inhibitor JM-2987 (B). Boxes represent median and interquartile range of values. Median values were compared in an inter-patient and in an intra-patient assay, using a Mann-Whitney test. Baseline samples (white boxes) and V38A mutant clones (gray boxes). ${ }^{* a} p=0.031,{ }^{*} p=0.0213,{ }^{* *} p=0.0038$, and ns non-significant differences. 
N140I [38]. Because there were no significant differences in fusogenicity among the Envs tested in our assays, we specifically quantified Env-mediated cell death, since in vitro the single-amino-acid mutation V38A/E has been shown to alter this mechanism [43]. HeLa cells expressing recombinant Envs were cocultured with primary $\mathrm{CD}^{+} \mathrm{T}$ cells. After 24 hours, the culture was stained with propidium iodide $(\mathrm{PI})$ and $\mathrm{DiOC}_{6}(3)$ to simultaneously determine the viability and the mitochondrial transmembrane potential of $\mathrm{CD}^{+} \mathrm{T}$ cells, respectively. Each Env was analysed in the absence and presence of the anti-CXCR4 antagonist JM-2987, and a correction for non-Env-mediated death was performed for each Env by subtracting the background death detected in the presence of JM-2987. When an intra-patient analysis of this assay was performed, there were differences between the recombinant clones carrying the V38A mutation and the wt clones in an N140I background, while the clones bearing the $\mathrm{N}$ or $\mathrm{T}$ amino acids at position 140 showed similar apoptosis-inducing capacity when wt and V38A clones were compared (Figure $4 \mathrm{~B})$. Thus, the impaired ability to deplete $\mathrm{CD}^{+} \mathrm{T}$ cells by the recombinant Envs that contained the cluster of mutations $\mathrm{V} 38 \mathrm{~A}+\mathrm{N} 140 \mathrm{I}$ in the gp41 protein was associated with a significant reduction in apoptosis induction on primary cells $(13.4 \%$ and $7.4 \%$ for baseline and with the cluster of mutation samples, respectively; $\mathrm{p}=$ 0.031 ). In agreement with previously reported in vivo data [38], both the absolute loss of $\mathrm{CD}^{+} \mathrm{T}$ cells and Env-induced single cell death was significantly reduced for Envs that had the cluster of mutations V38A + N140I. However, the acquisition of the V38A mutation in a gp41 background containing an $\mathrm{N}$ or $\mathrm{T}$ at position 140 had no significant impact on the pathogenicity of Env, again highlighting the importance of the genetic context on the function of Env. Polymorphisms in HR2 have been shown to contribute to ENF resistance [45], and in this study, we demonstrate that they also have an important role in HIV pathogenesis. Nevertheless, a methodological limitation of our study is the relative small number of clones analyzed which gives us a low statistical power. A larger sample size would allow a more accurate estimation of the differences studied.

Recently, it has been reported that caveolin-1 modulates the Env-induced bystander apoptosis through interactions with gp41. None of the clones obtained from the patient carrying the N140I mutation in gp41 showed changes in the caveolin binding region, suggesting that the changes in the induction of bystander apoptosis observed in this study are not due to a defect in the binding of this protein to the gp41 protein.

\section{Conclusions}

Overall, the phenotype observed in the present study for Envs containing the cluster of mutations V38A+N140I, which maintained fusion capacity, but had a decreased ability to deplete $\mathrm{CD} 4^{+} \mathrm{T}$ cells, correlated with the observed in vivo data in patients, including a maintenance of viral load with an increase in CD4 counts. These results show that mutations that confer ENF resistance are associated with reduced pathogenicity in vivo.

In conclusion, these findings support the hypothesis that HIV gp41 is a critical mediator of HIV pathogenesis and suggest that it may be possible to target gp41 to attenuate HIV.

\section{Methods}

\section{Patients}

Three highly-experienced patients who were receiving an ENF-containing salvage therapy were selected from our previous study [29]. These patients carried viruses that developed mutations at position 38 in the gp 41 viral protein associated with drug resistance and had different changes at position 140. Two plasma samples from each patient were collected at baseline and during ENF treatment and were used to extract viral RNA.

\section{Cell cultures and reagents}

HeLa and TZM-bl cell lines were supplied by the NIH AIDS Research and Reference Program. The cell lines were grown in Dulbecco's modified Eagle's medium (DMEM) supplemented with $10 \%$ of heat-inactivated fetal calf serum (FCS) and maintained at $37^{\circ} \mathrm{C}$ in a $5 \%$ $\mathrm{CO}_{2}$ incubator. Peripheral blood mononuclear cells (PBMCs) were freshly isolated from buffy coats obtained from a local blood bank (Banc de Sang i Teixits, BST), and $\mathrm{CD}^{+} \mathrm{T}$ cells were purified by negative immunomagnetic selection (Miltenyi Biotec, Spain). The final cell preparations were composed of $>95 \% \mathrm{CD}^{+} \mathrm{T}$ cells as determined by flow cytometry. The isolated $\mathrm{CD} 4^{+} \mathrm{T}$ cells were incubated overnight at $37^{\circ} \mathrm{C}$ in RPMI media supplemented with $10 \%$ of FCS prior to use. All of the media were purchased from Invitrogen (Madrid, Spain).

The CXCR4 antagonist JM-2987 (hydrobromide salt of AMD-3100) [59] and the CCR5 antagonist TAK-779 $[60,61]$ were obtained through the NIH AIDS Research and Reference Program. The broadly gp120 neutralizing antibody 2G12 and the secondary antibody goat antiHuman IgG were obtained from Polymun (Vienna, Austria) and Jackson ImmunoResearch Laboratories (Pennsylvania, USA), respectively. The Tat expression plasmid pcTat was obtained through the NIH AIDS Research and Reference Reagent Program [62]. 
The cell tracker Dichloro-DimethylAcridin-One (DDAO) was purchased from Molecular Probes (Invitrogen, Madrid, Spain). The cationic fluorescent dye Propidium Iodide (PI) and the potentiometric mitochondrial probe $\mathrm{DIOC}_{6}(3)$ were purchased from Sigma (Madrid, Spain) and Invitrogen, respectively.

\section{Plasmid construction}

The RNA from the plasma samples was isolated before and after the initiation of ENF treatment using the QIAmp Viral RNA kit (Qiagen). Full-length env/rev genes were amplified through RT-PCR using specific primers as previously described [63]. A subsequent nested PCR was carried out using Platinum ${ }^{\mathbb{R}}$ Taq DNA Polymerase High Fidelity (Invitrogen) to obtain a fragment corresponding to the gp41 protein (primers MluF2 and RNANestedR corresponding to nucleotides 7726-7747 and 8882-8904 of the $\mathrm{HIV}_{\text {HXB2 }}$ numbering system, respectively). A fragment corresponding to the gp120 protein was amplified from a NL4-3 plasmid (primers RNANestedF and MluR2 corresponding to nucleotides 5954-5983 and 7727-7747 of the $\mathrm{HIV}_{\text {HXB2 }}$ numbering system, respectively). The purified gp41 and gp120 products, which overlapped each other in 22 bases, were combined by PCR and purified to obtain the recombinant Envs (gp120 from NL4-3 and gp41 from patients). A directional cloning reaction was performed to insert the fragment into the plasmid expression vector pcDNA.3.1D/V5/His-TOPO (Invitrogen), and several transformed bacterial colonies were selected for each sample. All recombinant plasmids were sequenced using specific primers, the Big Dye Terminator v3.1 cycle sequencing kit (Applied Biosystems) and an automatic DNA Sequencer (3100 Genetic Analyzer). The sequences were edited (using Sequencher, v4.7, from the Gene Codes Corporation, Ann Arbor, MI and GeneDoc, v2.6, software), and the recombinant plasmids with the required mutations were selected.

\section{Transfections}

HeLa cells were plated at a density of $8 \times 105$ cells/well in six-well plates and allowed to grow overnight. The cells were transiently transfected (using Lipofectamine 2000 Reagent, Invitrogen, Spain) with $1.3 \mu \mathrm{g}$ of the Envexpressing plasmids for the cocultures with primary cells or were cotransfected with the Env-expressing plasmids and $2.7 \mu \mathrm{g}$ of pcTat for the fusion assays. Twentyfour hours post-transfection, the cells were collected for further analyses. As negative controls, cells were mocktransfected (with the pcDNA 3.1 vector) or transfected with pcTat alone.

\section{Envelope expression}

Twenty-four hours post-transfection, cell membrane expression of the Env glycoprotein was assessed by flow cytometry after indirect staining with the anti-gp120 monoclonal antibody $2 \mathrm{G} 12(4 \mu \mathrm{g} / \mathrm{ml})$ for $20 \mathrm{~min}$ at $37^{\circ}$ $\mathrm{C}$, followed by staining with phycoerythrin-labeled goat anti-human IgG (RT for $15 \mathrm{~min}$ ). The cells were washed, fixed in $1 \%$ formaldehyde and analyzed by a FACS LSRII flow cytometer. The data were analyzed using FACSDiva software (BD Biosciences). Mock-transfected cells were used as a negative staining control. The percentage of Env-positive cells and the geometric mean fluorescence intensity (geoMFI) of these cells were considered as individual parameters or used to calculate the relative fluorescence intensity (RFI $=\%$ of Env-positive cells $\times$ geoMFI of Env-positive cells), as described previously [50].

\section{Cell-to-Cell Fusion assays}

Twenty-four hours post-transfection, Env/pcTat- and pcTat-transfected HeLa cells were cocultured with the reporter cell line $\mathrm{CD} 4^{+} / \mathrm{CCR} 5^{+} / \mathrm{CXCR} 4^{+} \mathrm{TZM}$-bl for 6 hours in 96-well plates in the presence or absence of the CXCR4 and CCR5 co-receptor inhibitors JM-2987 and TAK-779 $(1 \mu \mathrm{g} / \mathrm{ml})$, respectively. The fusion efficiency of each clone was quantified by assessing the luminescence of the cells (Britelite kit, Perkin Elmer) with a Luminoskan Ascent luminometer (Labsystems, Spain).

\section{Envelope-induced death in primary $\mathrm{CD}^{+} \mathrm{T}$ cells: absolute cell loss and bystander apoptosis}

Env-induced cytopathic effects were evaluated using a coculture system of Env-expressing HeLa cells as effector cells and labeled primary $\mathrm{CD} 4^{+} \mathrm{T}$ cells as target cells. The primary $\mathrm{CD} 4^{+} \mathrm{T}$ cells were stained with the far red cell tracker, DDAO $(10 \mu \mathrm{g} / \mathrm{mL})$, for 1 hour at $37^{\circ} \mathrm{C}$. $\mathrm{Env}^{+} \mathrm{HeLa}$ cells and $\mathrm{CD} 4^{+} / \mathrm{DDAO}^{+} \mathrm{T}$ cells were cocultured for 24 hours in the absence and presence of the inhibitor, JM-2987 $(1 \mu \mathrm{g} / \mathrm{mL})$, and were stained with $\mathrm{DiOC}_{6}(3)(40 \mathrm{nM})$ and PI $(5 \mu \mathrm{g} / \mathrm{mL})$ for 1 hour at $37^{\circ} \mathrm{C}$. Labeled microbeads (Beads Perfect Count, Invitrogen) were added to the stained coculture to quantify the absolute cell loss, and flow cytometry was performed by a FACS LSRII flow cytometer. The data were analyzed by the FACSDiva software (BD Biosciences).

\section{Statistical analyses}

The data were compared using non-parametric MannWhitney tests. All statistical analyses were performed using GraphPad Prism, version 5.01, for Windows (GraphPad Software, San Diego, California, USA). A P-value of 0.05 was considered to be significant for these studies.

\section{Acknowledgements}

This work was supported by the FIS project 07/0418 (to CC), the Spanish AIDS network, "RIS, Red Temática Cooperativa de Investigación en SIDA 
(RD06/0006)" and the CHAIN European Consortium. C. Cabrera and J. Blanco are researchers from Fundació Institut de Recerca en Ciències de la Salut Germans Trias i Pujol supported by the Health Department of the Catalan Government (Generalitat de Catalunya). F. Cunyat is supported by the FIS project 07/0418 and VS is supported by grants from CHAIN, Collaborative HIV and Anti-HIV Drug-Resistance Network, Integrated Project no.223131, funded by the European-Commission Framework-7 Program. MC is supported by a RIS contract. This work is part of the PhD thesis of F. Cunyat at Universitat Autònoma de Barcelona, Barcelona, Spain.

\section{Author details}

${ }^{1}$ IrsiCaixa-HIVACAT, Institut de Recerca en Ciències de la Salut Germans Trias i Pujol (IGTP), Hospital Germans Trias, Universitat Autònoma de Barcelona, Badalona 08916 Barcelona, Catalonia, Spain. ${ }^{2}$ Department of Experimental Medicine. University of "Tor Vergata," Rome, Italy. ${ }^{3}$ Lluita contra la SIDA Foundation, Institut de Recerca en Ciències de la Salut Germans Trias i Pujol, Hospital Universitari Germans Trias i Pujol, Universitat Autònoma de Barcelona, 08916 Badalona, Barcelona, Spain. ${ }^{4}$ Statistics and Operation Research Department, Universitat Politècnica de Catalunya, Barcelona, Spain.

\section{Authors' contributions}

$F C$, JB and CC together designed this study. FC, EG and MC performed the plasmid constructions, the fusogenicity and the cell depletion assays. FC and N P-A performed the statistical analysis. FC, VS, CP, JB and CC drafted and edited this manuscript. SM was responsible for sequencing the Envs. All authors have read and approved the final manuscript.

\section{Competing interests}

The authors declare that they have no competing interests.

Received: 9 November 2011 Accepted: 14 February 2012

Published: 14 February 2012

\section{References}

1. Hazenberg MD, Hamann D, Schuitemaker H, Miedema F: T cell depletion in HIV-1 infection: how CD4+ T cells go out of stock. Nat Immunol 2000, 1(4):285-9.

2. McCune JM: The dynamics of CD4+ T-cell depletion in HIV disease. Nature 2001, 410(6831):974-9.

3. Finkel TH, Banda NK: Indirect mechanisms of HIV pathogenesis: how does HIV kill T cells? Curr Opin Immunol 1994, 6(4):605-15.

4. Gandhi RT, Chen BK, Straus SE, Dale JK, Lenardo MJ, Baltimore D: HIV-1 directly kills CD4+ T cells by a Fas-independent mechanism. J Exp Med 1998, 187(7):1113-22.

5. Douek DC, Roederer M, Koup RA: Emerging concepts in the immunopathogenesis of AIDS. Annu Rev Med 2009, 60:471-84

6. Ameisen JC, Capron A: Cell dysfunction and depletion in AIDS: the programmed cell death hypothesis. Immunol Today 1991, 12(4):102-5.

7. Gougeon ML: Apoptosis as an HIV strategy to escape immune attack. Nat Rev Immunol 2003, 3(5):392-404.

8. Perfettini $J$, Castedo M, Roumier T, Andreau K, Nardacci R, Piacentini M, Kroemer G: Mechanisms of apoptosis induction by the HIV-1 envelope. Cell Death Differ 2005, 12(Suppl 1):916-23.

9. Badley AD, Pilon AA, Landay A, Lynch DH: Mechanisms of HIV-associated lymphocyte apoptosis. Blood 2000, 96(9):2951-64.

10. Gougeon ML, Montagnier L: Apoptosis in AIDS. Science 1993, 260(5112):1269-70

11. Doitsh G, Cavrois M, Lassen KG, Zepeda O, Yang Z, Santiago ML, Hebbeler AM, Greene WC: Abortive HIV infection mediates CD4 T cell depletion and inflammation in human lymphoid tissue. Cell 2010, 143(5):789-801.

12. Doms RW, Moore JP: HIV-1 membrane fusion: targets of opportunity. J Cell Biol 2000, 151(2):F9-14.

13. Doms RW, Trono D: The plasma membrane as a combat zone in the HIV battlefield. Genes Dev 2000, 14(21):2677-88.

14. Eckert DM, Kim PS: Mechanisms of viral membrane fusion and its inhibition. Annu Rev Biochem 2001, 70:777-810.

15. Ferri KF, Jacotot E, Blanco J, Este JA, Zamzami N, Susin SA, Xie Z, Brothers G, Reed JC, Penninger JM, Kroemer G: Apoptosis control in syncytia induced by the HIV type 1-envelope glycoprotein complex: role of mitochondria and caspases. J Exp Med 2000, 192(8):1081-92.
16. Ahr B, Robert-Hebmann V, Devaux C, Biard-Piechaczyk M: Apoptosis of uninfected cells induced by HIV envelope glycoproteins. Retrovirology 2004, 1:12.

17. Moore JP, McKeating JA, Weiss RA, Sattentau QJ: Dissociation of gp120 from HIV-1 virions induced by soluble CD4. Science 1990, 250(4984):1139-42

18. Willey RL, Martin MA: Association of human immunodeficiency virus type 1 envelope glycoprotein with particles depends on interactions between the third variable and conserved regions of gp120. J Virol 1993, 67(6):3639-43.

19. Wyatt R, Sodroski J: The HIV-1 envelope glycoproteins: fusogens, antigens, and immunogens. Science 1998, 280(5371):1884-8.

20. Roux KH, Taylor KA: AIDS virus envelope spike structure. Curr Opin Struct Biol 2007, 17(2):244-52.

21. Wild C, Dubay JW, Greenwell T, Baird T Jr, Oas TG, McDanal C, Hunter E, Matthews T: Propensity for a leucine zipper-like domain of human immunodeficiency virus type $1 \mathrm{gp} 41$ to form oligomers correlates with a role in virus-induced fusion rather than assembly of the glycoprotein complex. Proc Natl Acad Sci USA 1994, 91(26):12676-80.

22. Wild CT, Shugars DC, Greenwell TK, McDanal CB, Matthews TJ: Peptides corresponding to a predictive alpha-helical domain of human immunodeficiency virus type $1 \mathrm{gp} 41$ are potent inhibitors of virus infection. Proc Natl Acad Sci USA 1994, 91(21):9770-4.

23. Kilgore NR, Salzwedel K, Reddick M, Allaway GP, Wild CT: Direct evidence that C-peptide inhibitors of human immunodeficiency virus type 1 entry bind to the gp41 N-helical domain in receptor-activated viral envelope. J Virol 2003, 77(13):7669-72

24. Cervia JS, Smith MA: Enfuvirtide (T-20): a novel human immunodeficiency virus type 1 fusion inhibitor. Clin Infect Dis 2003, 37(8):1102-6.

25. Kilby JM, Hopkins S, Venetta TM, DiMassimo B, Cloud GA, Lee JY, Alldredge L, Hunter E, Lambert D, Bolognesi D, Matthews T, Johnson MR, Nowak MA, Shaw GM, Saag MS: Potent suppression of HIV-1 replication in humans by $\mathrm{T}-20$, a peptide inhibitor of gp41-mediated virus entry. Nat Med 1998, 4(11):1302-7.

26. Lazzarin A, Clotet B, Cooper D, Reynes J, Arasteh K, Nelson M, Katlama C, Stellbrink HJ, Delfraissy JF, Lange J, Huson L, DeMasi R, Wat C, Delehanty J, Drobnes C, Salgo M: Efficacy of enfuvirtide in patients infected with drug-resistant HIV-1 in Europe and Australia. N Engl J Med 2003, 348(22):2186-95.

27. Lalezari JP, Henry K, O'Hearn M, Montaner JS, Piliero PJ, Trottier B, Walmsley S, Cohen C, Kuritzkes DR, Eron JJ Jr, Chung J, DeMasi R, Donatacci L, Drobnes C, Delehanty J, Salgo M: Enfuvirtide, an HIV-1 fusion inhibitor, for drug-resistant HIV infection in North and South America. N Engl J Med 2003, 348(22):2175-85.

28. Bonjoch A, Negredo E, Puig J, Erkizia I, Puig T, Cabrera C, Ruiz L, Clotet B: Viral failure in HIV-infected patients with long-lasting viral suppression who discontinued enfuvirtide. AIDS 2006, 20(14):1896-8.

29. Cabrera C, Marfil S, Garcia E, Martinez-Picado J, Bonjoch A, Bofill M, Moreno S, Ribera E, Domingo P, Clotet B, Ruiz L: Genetic evolution of gp41 reveals a highly exclusive relationship between codons 36,38 and 43 in gp41 under long-term enfuvirtide-containing salvage regimen. AIDS 2006, 20(16):2075-80.

30. Wei X, Decker JM, Liu H, Zhang Z, Arani RB, Kilby JM, Saag MS, Wu X, Shaw GM, Kappes JC: Emergence of resistant human immunodeficiency virus type 1 in patients receiving fusion inhibitor (T-20) monotherapy. Antimicrob Agents Chemother 2002, 46(6):1896-905

31. Lu J, Deeks SG, Hoh R, Beatty G, Kuritzkes BA, Martin JN, Kuritzkes DR: Rapid emergence of enfuvirtide resistance in HIV-1-infected patients: results of a clonal analysis. J Acquir Immune Defic Syndr 2006, 43(1):60-4.

32. Ray N, Blackburn LA, Doms RW: HR-2 mutations in human immunodeficiency virus type $1 \mathrm{gp} 41$ restore fusion kinetics delayed by HR-1 mutations that cause clinical resistance to enfuvirtide. J Virol 2009, 83(7):2989-95

33. Reeves JD, Gallo SA, Ahmad N, Miamidian JL, Harvey PE, Sharron M, Pohlmann S, Sfakianos JN, Derdeyn CA, Blumenthal R, Hunter E, Doms RW: Sensitivity of HIV-1 to entry inhibitors correlates with envelope/ coreceptor affinity, receptor density, and fusion kinetics. Proc Natl Acad Sci USA 2002, 99(25):16249-54.

34. Tolstrup M, Selzer-Plon J, Laursen AL, Bertelsen L, Gerstoft J, Duch M, Pedersen FS, Ostergaard L: Full fusion competence rescue of the 
enfuvirtide resistant HIV-1 gp41 genotype (43D) by a prevalent polymorphism (137K). AIDS 2007, 21(4):519-21.

35. Xu L, Pozniak A, Wildfire A, Stanfield-Oakley SA, Mosier SM, Ratcliffe D, Workman J, Joall A, Myers R, Smit E, Cane PA, Greenberg ML, Pillay D: Emergence and evolution of enfuvirtide resistance following long-term therapy involves heptad repeat 2 mutations within gp 41. Antimicrob Agents Chemother 2005, 49(3):1113-9.

36. Jenwitheesuk E, Samudrala R: Heptad-repeat-2 mutations enhance the stability of the enfuvirtide-resistant HIV-1 gp41 hairpin structure. Antivir Ther 2005, 10(8):893-900.

37. Baatz F, Nijhuis $M$, Lemaire M, Riedijk M, Wensing AM, Servais JY, van Ham PM, Hoepelman Al, Koopmans PP, Sprenger HG, Devaux C, Schmit JC, Perez Bercoff D: Impact of the HIV-1 env genetic context outside HR1HR2 on resistance to the fusion inhibitor enfuvirtide and viral infectivity in clinical isolates. PLOS One 2011, 6(7):e21535.

38. Svicher V, Aquaro S, D'Arrigo R, Artese A, Dimonte S, Alcaro S, Santoro MM, Di Perri G, Caputo SL, Bellagamba R, Zaccarelli M, Visco-Comandini U, Antinori A, Narciso P, Ceccherini-Silberstein F, Perno CF: Specific enfuvirtide-associated mutational pathways in HIV-1 Gp41 are significantly correlated with an increase in CD4(+) cell count, despite virological failure. J Infect Dis 2008, 197(10):1408-18.

39. Aquaro S, D'Arrigo R, Svicher V, Perri GD, Caputo SL, Visco-Comandini U, Santoro M, Bertoli A, Mazzotta F, Bonora S, Tozzi V, Bellagamba R, Zaccarelli M, Narciso P, Antinori A, Perno CF: Specific mutations in HIV-1 gp41 are associated with immunological success in HIV-1-infected patients receiving enfuvirtide treatment. J Antimicrob Chemother 2006, 58(4): $: 714-22$.

40. Melby TE, Despirito M, Demasi RA, Heilek G, Thommes JA, Greenberg ML, Graham N: Association between specific enfuvirtide resistance mutations and CD4 cell response during enfuvirtide-based therapy. AIDS 2007, 21(18):2537-9.

41. Blanco J, Barretina J, Ferri KF, Jacotot E, Gutierrez A, Armand-Ugon M, Cabrera C, Kroemer G, Clotet B, Este JA: Cell-surface-expressed HIV-1 envelope induces the death of CD4 T cells during GP41-mediated hemifusion-like events. Virology 2003, 305(2):318-29.

42. Garg H, Joshi A, Freed EO, Blumenthal R: Site-specific mutations in HIV-1 gp41 reveal a correlation between HIV-1-mediated bystander apoptosis and fusion/hemifusion. J Biol Chem 2007, 282(23):16899-906

43. Garg H, Joshi A, Blumenthal R: Altered bystander apoptosis induction and pathogenesis of enfuvirtide-resistant HIV type 1 Env mutants. AIDS Res Hum Retroviruses 2009, 25(8):811-7.

44. Garg H, Joshi A, Ye C, Shankar P, Manjunath N: Single amino acid change in gp41 region of HIV-1 alters bystander apoptosis and CD4 decline in humanized mice. Virol J 2011, 8:34.

45. Goubard A, Clavel F, Mammano F, Labrosse B: In vivo selection by enfuvirtide of HIV type-1 env quasispecies with optimal potential for phenotypic expression of HR1 mutations. Antivir Ther 2009, 14(4):597-602.

46. Labrosse B, Morand-Joubert L, Goubard A, Rochas S, Labernardiere JL, Pacanowski J, Meynard JL, Hance AJ, Clavel F, Mammano F: Role of the envelope genetic context in the development of enfuvirtide resistance in human immunodeficiency virus type 1-infected patients. J Virol 2006, 80(17):8807-19.

47. Wang XM, Nadeau PE, Lo YT, Mergia A: Caveolin-1 modulates HIV-1 envelope-induced bystander apoptosis through gp41. J Virol 2010, 84(13):6515-26.

48. Tersmette M, Lange JM, de Goede RE, de Wolf F, Eeftink-Schattenkerk JK, Schellekens PT, Coutinho RA, Huisman JG, Goudsmit J, Miedema F: Association between biological properties of human immunodeficiency virus variants and risk for AIDS and AIDS mortality. Lancet 1989, 1(8645):983-5.

49. Blanco J, Barretina J, Clotet B, Este JA: R5 HIV gp120-mediated cellular contacts induce the death of single CCR5-expressing CD4 T cells by a gp41-dependent mechanism. J Leukoc Biol 2004, 76(4):804-11.

50. Sterjovski J, Churchill MJ, Ellett A, Gray LR, Roche MJ, Dunfee RL, Purcell DF, Saksena N, Wang B, Sonza S, Wesselingh SL, Karlsson I, Fenyo EM, Gabuzda D, Cunningham AL, Gorry PR: Asn 362 in gp120 contributes to enhanced fusogenicity by CCR5-restricted HIV-1 envelope glycoprotein variants from patients with AIDS. Retrovirology 2007, 4:89.

51. Karlsson GB, Halloran M, Schenten D, Lee J, Racz P, Tenner-Racz K, Manola J, Gelman R, Etemad-Moghadam B, Desjardins E, Wyatt R, Gerard NP, Marcon L, Margolin D, Fanton J, Axthelm MK, Letvin NL, Sodroski J: The envelope glycoprotein ectodomains determine the efficiency of CD4+ T lymphocyte depletion in simian-human immunodeficiency virus-infected macaques. J Exp Med 1998, 188(6):1159-71.

52. Etemad-Moghadam B, Sun Y, Nicholson EK, Fernandes M, Liou K, Gomila R, Lee J, Sodroski J: Envelope glycoprotein determinants of increased fusogenicity in a pathogenic simian-human immunodeficiency virus (SHIV-KB9) passaged in vivo. J Virol 2000, 74(9):4433-40.

53. Etemad-Moghadam B, Rhone D, Steenbeke T, Sun Y, Manola J, Gelman R, Fanton JW, Racz P, Tenner-Racz K, Axthelm MK, Letvin NL, Sodroski J: Membrane-fusing capacity of the human immunodeficiency virus envelope proteins determines the efficiency of $C D+T$-cell depletion in macaques infected by a simian-human immunodeficiency virus. J Virol 2001, 75(12):5646-55.

54. LaBonte JA, Patel T, Hofmann W, Sodroski J: Importance of membrane fusion mediated by human immunodeficiency virus envelope glycoproteins for lysis of primary CD4-positive T cells. J Virol 2000, 74(22):10690-8.

55. Chen SS, Yang P, Ke PY, Li HF, Chan WE, Chang DK, Chuang CK, Tsai Y, Huang SC: Identification of the LWYIK motif located in the human immunodeficiency virus type 1 transmembrane gp 41 protein as a distinct determinant for viral infection. J Virol 2009, 83(2):870-83.

56. Gougeon ML, Lecoeur H, Dulioust A, Enouf MG, Crouvoiser M, Goujard C, Debord T, Montagnier L: Programmed cell death in peripheral lymphocytes from HIV-infected persons: increased susceptibility to apoptosis of CD4 and CD8 T cells correlates with lymphocyte activation and with disease progression. J Immunol 1996, 156(9):3509-20.

57. Debatin KM, Fahrig-Faissner A, Enenkel-Stoodt S, Kreuz W, Benner A, Krammer PH: High expression of APO-1 (CD95) on T lymphocytes from human immunodeficiency virus-1-infected children. Blood 1994, 83(10):3101-3.

58. Finkel TH, Tudor-Williams G, Banda NK, Cotton MF, Curiel T, Monks C, Baba TW, Ruprecht RM, Kupfer A: Apoptosis occurs predominantly in bystander cells and not in productively infected cells of HIV- and SIVinfected lymph nodes. Nat Med 1995, 1(2):129-34.

59. De Clercq E, Yamamoto N, Pauwels R, Balzarini J, Witvrouw M, De Vreese K, Debyser Z, Rosenwirth B, Peichl P, Datema R, Thornton D, Skerlj R, Gaul F, Padmanabhan S, Bridger G, Henson G, Abrams M: Highly potent and selective inhibition of human immunodeficiency virus by the bicyclam derivative JM3100. Antimicrob Agents Chemother 1994, 38(4):668-74

60. Baba M, Nishimura O, Kanzaki N, Okamoto M, Sawada H, lizawa Y, Shiraishi M, Aramaki Y, Okonogi K, Ogawa Y, Meguro K, Fujino M: A smallmolecule, nonpeptide CCR5 antagonist with highly potent and selective anti-HIV-1 activity. Proc Natl Acad Sci USA 1999, 96(10):5698-703.

61. Dragic T, Trkola A, Thompson DA, Cormier EG, Kajumo FA, Maxwell E, Lin SW, Ying W, Smith SO, Sakmar TP, Moore JP: A binding pocket for a small molecule inhibitor of HIV-1 entry within the transmembrane helices of CCR5. Proc Natl Acad Sci USA 2000, 97(10):5639-44.

62. Malim MH, Hauber J, Fenrick R, Cullen BR: Immunodeficiency virus rev trans-activator modulates the expression of the viral regulatory genes. Nature 1988, 335(6186):181-3.

63. Li M, Gao F, Mascola JR, Stamatatos L, Polonis VR, Koutsoukos M, Voss G, Goepfert P, Gilbert P, Greene KM, Bilska M, Kothe DL, Salazar-Gonzalez JF, Wei X, Decker JM, Hahn BH, Montefiori DC: Human immunodeficiency virus type 1 env clones from acute and early subtype B infections for standardized assessments of vaccine-elicited neutralizing antibodies. J Virol 2005, 79(16):10108-25.

doi:10.1186/1742-4690-9-15

Cite this article as: Cunyat et al: The HR2 polymorphism N140I in the HIV-1 gp41 combined with the HR1 V38A mutation is associated with a less cytopathic phenotype. Retrovirology 2012 9:15. 